\title{
An assessment of the quality of care provided at primary health care centres in camps for internally displaced persons in Iraq in 2018
}

Muhammad Fawad Khan ${ }^{1 *}$, Daniel Jeannetot ${ }^{2}$, Kamal Sunil Olleri ${ }^{1}$, Mirjam Bakker ${ }^{3}$, Altaf Sadrudin Musani ${ }^{1}$, Adham Rashad Ismail Abdel Moneim ${ }^{1}$, Wael Hatahit ${ }^{1}$ and Prisca Zwanikken ${ }^{3}$

\begin{abstract}
Introduction: The humanitarian crisis in Iraq remains one of the largest and most unstable in the world. In 2014, over 2.5 million civilians were displaced in Iraq; between 2015 and 2017 more than 3 million people continued to be displaced. While health-related research concerning internally displaced persons (IDPs) population has been conducted in many settings, very few have looked at the quality of care delivered in primary health care centres (PHCC) inside camps. The objective of this operational research is to assess the quality of health care services at PHCC in operational IDP camps supported by local and international NGOs (humanitarian partners) as well as the Directorate of Health $(\mathrm{DoH})$ in Iraq at baseline and after 6 months.
\end{abstract}

Method: A framework based on five components was used to assess quality of care by assigning a quality-of-care index score. Using a longitudinal design; data were collected through observations of facilities and of patient consultations, as well as health worker and patient exit interviews, in static PHCC in operational IDP camps of Iraq during two different phases: in June $(n=55)$, and December $2018(n=47)$. These facilities supported more than 500,000 IDPs. Descriptive and statistical analyses were conducted, and the results compared.

Result: For all camps $(n=47)$, the average overall quality of care index score increased between the two phases. No specific type of organisation consistently provided a better quality of care. The camp size was unrelated to the quality of care provided at the respective facility. The domain indicators "Client Care" and "Environment and Safety" mostly related to the variation in the general assessment of quality. Patient satisfaction was unrelated to any other domain score. Compared at 0 and after 6 -months, the quality of care index score between the type of organisation and governorate showed that feedback positively impacted service delivery after the first assessment. Positive differences in scores also appeared, with notable improvements in Client care and Technical competence.

Conclusion: Humanitarian partners and the DoH are able to provide quality care, independent of camp size or the number of camps managed, and their cooperation can lead to quick improvements. This research also shows that quality of care assessment in emergency settings can be carried out in formal IDP camps using non-emergency standards.

Keywords: Internally displaced persons, Quality of care, Camp, Iraq, Primary health care, Complex emergencies

*Correspondence: khanmu@who.int

${ }^{1}$ WHO Country Office - Iraq, Baghdad, Iraq

Full list of author information is available at the end of the article permits use, sharing, adaptation, distribution and reproduction in any medium or format, as long as you give appropriate credit to the original author(s) and the source, provide a link to the Creative Commons licence, and indicate if changes were made. The images or other third party material in this article are included in the article's Creative Commons licence, unless indicated otherwise in a credit line to the material. If material is not included in the article's Creative Commons licence and your intended use is not permitted by statutory regulation or exceeds the permitted use, you will need to obtain permission directly from the copyright holder. To view a copy of this licence, visit http://creativecommons.org/licenses/by/4.0/. The Creative Commons Public Domain Dedication waiver (http://creativeco mmons.org/publicdomain/zero/1.0/) applies to the data made available in this article, unless otherwise stated in a credit line to the data. 


\section{Introduction}

After the Emergency Relief Coordinator of the InterAgency Standing Committee (IASC) declared Iraq to be a "Level 3 emergency" in 2015, the highest on the humanitarian crisis scale, emergency funding channelled through Humanitarian Response Plans was made available to provide assistance and relief to the Iraqi population through the Cluster Approach. ${ }^{1}$ Over a period of 5 years, more than six million people were displaced [1], $18 \%$ of the population. As early as 2016, the situation had partially stabilised and people started returning home [1]. In December 2017, the government of Iraq officially declared victory over the Islamic State in Iraq and Levant (ISIL) group [2]. In 2019, more than 1.7 million people were still displaced and in need of assistance with shelter, protection, and health services among other basic needs, with almost $30 \%$ still staying in camps [3].

Jordan et al. point at the large gap in measuring quality both at the point of care and at the health system level [4]. In humanitarian contexts globally, many aspects of health have been assessed in the literature for refugee or internally displaced persons (IDPs), camps setting (e.g., health status, access, acceptability) [5-9], however quality of care has not been directly assessed.

\section{Literature review}

Quality of care is widely researched in high-income countries, but studies have rarely been conducted in emergency or post-emergency settings [10]. The focus of most research on health care provision in emergency and postemergency settings is on outcomes indicators [11-16] where the priority is mortality reduction. Nonetheless, the concept of quality of care exists in key documents: the SPHERE standards [17], which provides minimum standards for all aspects in humanitarian response, e.g. health service delivery, are used to benchmark the quality of care provided. Regarding health service delivery, SPHERE stipulates that "People have access to integrated quality healthcare that is safe, effective, and patient-centred," but does not mention the quality of care as understood in non-emergency contexts [17] and as defined by the WHO: "the extent to which health care services provided to individuals and patient populations improve desired health outcomes. In order to achieve this, health care must be safe, effective, timely, efficient, equitable and people-centered" [18]. In its 2014-2018 Global Strategy for Public Health, UNHCR set its first objective to be "[To] Improve access to quality primary health care programmes" [19]. In fact, the SPHERE standards have not

\footnotetext{
${ }^{1}$ An international coordination architecture set at the global level to coordinate humanitarian emergency response, by the IASC and partners.
}

all been based on evidence, but mostly on what is considered best practice by the humanitarian community, since evidence can be difficult to generate, verify, and generalise in such settings [20,21]. Beyond the quality of care, the focus has more often been on the quality of life in camps, either for refugees or IDPs, which includes aspects of health care services [22-25]. Most studies in IDP camps measure quality as set by SPHERE standards, others focus on the outcomes of specialised care [26-29]. Only a few studies attempt to consistently evaluate the quality of health care provision using SPHERE standards. They include other components such as WASH or nutrition, extending beyond the scope of health service delivery quality [11, 30, 31]. Interestingly, instead of using SPHERE standards, Kersten et al. used quality as conceptualised by Donabedian, to demonstrate the feasibility of assessing the quality of care in emergency settings [10]. The necessity to move beyond SPHERE standards to assess the quality of care in emergency settings is also based on ethical principles: patients, including in humanitarian crises, have a right to quality of care.

The scarcity of evidence on the quality of care in health facilities in IDP camps joins the ongoing discussion regarding the lack of (quality) evidence from interventions in humanitarian settings. More broadly, the call for better evidence to feed practice and standards in (post-) emergency settings has been heard for many years, but slow to materialize in practice [32-36].

Quality of care has been defined in different ways in the literature [34-40]. For the purpose of the rapid assessment, the concept of quality of care used was defined by the Primary Health Care Initiative (PHCI) Quality Improvement Handbook of the Hashemite Kingdom of Jordan, because, in addition to providing a conceptual definition, it also provides a tool to operationalise the definition. This study therefore uses the same concept. The definition is: "the proper performance (according to standards) of interventions that are known to be safe, that are affordable, and acceptable to the society in question, and that have the ability to improve health outcomes and meet or exceed client expectations" [41]. The situation called for a rapidly implementable, context-sensitive, and deployable tool which was already operationalized.

There is an evidence gap in the quality of care in primary health care facilities in IDP camp settings [4], which this research attempts to fill. In 2018, the Health Cluster, led by WHO, initiated assessments of the quality of primary health care services provided at primary health care centres (PHCCs) in IDP camps in Iraq. The main purpose of these assessments was to give feedback to improve the quality of care provided by implementing partners, the secondary purpose, was to assess the feasibility of measuring the quality of care in IDP camps 
Table 1 Conceptual framework quality of care.

\begin{tabular}{ll}
\hline Technical competence & $\begin{array}{l}\text { Staff are competent to provide services for general and reproductive health conditions } \\
\text { Client care }\end{array}$ \\
The center provides information about services, health, and follow up care to ensure understanding compliance, confidenti- \\
ality, and satisfaction \\
The center plans, staffs, organizes and implements health delivery services to ensure efficiency and effectiveness for clients, \\
community, and staff members \\
Environment and safety \\
Satisfaction
\end{tabular}

Source: Quality improvement handbook for primary health care, 2004

through non-emergency standards. A summary of the results is available in the public domain [42, 43].

\section{Objective}

The primary objective of this operational research was to assess the quality of health care services provided at primary health care centres (PHCCs) in existing IDP camps in Iraq in 2018 at two points in time and provide recommendations on how to study quality of care in IDP camps to support future implementation. Secondary objectives included assessing how governorate, implementing partners, and camp population size could impact the quality of care of PHCC in IDP camps in emergency situations.

\section{IDP camps organisation in Iraq}

Health services in Iraqi IDP Camps were part of the camp management tool kit developed by the global Camp Coordination and Camp Management (CCCM) Cluster, which support standards and policies in managing displaced population in camps [44]. Health services in formal camps were run by local or international NGOs, some by the DoH (Governorate's Directorate of Health), all of which are part of the Health Cluster. All camps had one primary health care centre on-site, with staff provided by the Iraqi Ministry of Health and managed on-site by implementing partners. Camps with more than 10,000 individuals had increased staff capacity along with satellite health posts inside the camps and ambulatory maternal and childcare services. While PHCCs provide basic health care services, patients in need of reproductive and maternal health were directed to specific services for reproductive and maternal service organised separately. On average, staffing at PHCCs consisted of four general physicians, two nurses per general physician, a lead pharmacist, and a lead laboratory technician. In the most populous camp, a maximum of eight general physicians were present. The PHCCs only provided basic services, therefore when patients required more care, they were referred by the health partner to the nearest secondary-level health facility outside the camp by bus or ambulance and brought back after treatment.

\section{Methodology \\ Design}

This study had a longitudinal design using PHCC; data collection took place in June (Phase 1) and December (Phase 2) 2018. The findings of Phase 1 were provided to implementing partners to improve quality of care before Phase 2 took place.

\section{Indicators and data collection tool}

The definition of quality of care in the conceptual framework provided domains to deconstruct quality of care as shown in Table 1 and allowed it to be measured.

The conceptual framework is operationalised by a list of tested and tailored tools [41, 45]. The questions were adapted for reasons of efficiency and available resources in the given context. The data collection tool consisted of observations and interviews. Observations were a facility checklist with 13 items, and clinical care checklists for all health worker types during interactions with patients (Additional file 1). The interviews consisted of two subsets: one for all health workers with the same 5 questions, and one for patients with 22 questions. Questions in both the observation and interview sets were closed, in the form of Yes/No, or a three level Likert scale type (Additional file 1). Data collection took between 30 and $60 \mathrm{~min}$ per observation/interview.

\section{Unit of analysis, population and sample}

The unit of analysis were the IDP camp. Each camp was served by one general primary health facility, included in this study. The sample population was composed of all the camps listed in the CCCM Camp master list for Iraq. The sample included 55 camps in June 2018, and 47 in December 2018. The number of camps fell because of a decreased IDP count and the closure or consolidation of camps. Between June and December, 46 camps were 
the same and therefor comparable between the datasets, while the remaining camps were only existing in that specific period. General PHCCs were selected for the survey. Reproductive care facilities, which were separate facilities in the IDP camps in Iraq, although some reproductive health services were available in the PHCC, were excluded.

The samples of services providers and patients per facility consisted of four service providers: the on-duty physician and nurse in examination room one, the lead pharmacist, and the lead laboratory technician. Six patients were interviewed for the post-consultation questionnaire. The first patient leaving a consultation on the day of data collection was selected as the first respondent. The five others were picked at random using the roll of a die, selecting the nth patient at the exit of the facility according to the number rolled. Fourteen patients across the 55 camps in Phase 1 did not participate, all solicited patients participated in Phase 2. If a patient refused to participate, the next patient to come out of consultation was selected.

\section{Data collection protocol}

Data were collected in all PHCC run by the Health Cluster partners. The assessment took 4-6 days per governorate. The complete assessment took 1 day per facility. The data were collected using the Kobo Tool Box [46] a smartphone/tablet data collection tool. The observation checklists were in English, and the interviews were conducted in Arabic or Kurdish. The answers were collected in English. All enumerators knew English/Arabic/Kurdish and could translate the results accordingly.

The data collection was performed by teams comprising two trained enumerators from the Iraqi Red Crescent Society (IRCS), including a medical doctor for the observation assessment, and a pharmacist or dentist for the interviews. The teams were composed of one male and one female. There was a specific protocol for genderdisaggregated data collection. IRCS was selected as they did not support any PHCC services in the camps, limiting the chances of bias. Population and camp data were obtained from the IOM data matrix [47] as were base characteristics of the operation. Average family size, number of families per camp and female to male ratio were estimates. Age and sex-disaggregated data were not available because of setting constraints.

Patients seeking specific maternal and reproductive care were not captured in the patient exit interviews because the focus was on general primary care services. Thirteen INGO-supported camps were either closed, consolidated, or transferred to NGOs between Phase 1 and 2.

\section{Data management and analyses}

The data were cleaned and verified using Microsoft Excel, and analyzed using $\mathrm{R}$ and Rstudio [48, 49]. The data went through a visual and descriptive inspection, before being analyzed through linear regressions. No missing data point was found.

Each domain of the framework was assessed by a different set of questions, rated independently in percentages. The five domains were combined into an Index score from 0 to $100 \%$, with $100 \%$ corresponding to the highest standard of quality of care.

The domain scores were calculated based on the average answers per questions provided by a set of domainspecific questions and observations. The questions and observations were coded so that a positive answer would increase the score of the domain ("Yes" $=2$, "No" $=0$ and "None" $=0$, "Partial" $=1$, "All" =2). Within the domains, the questions were equally weighted. The maximum per domain was $100 \%$ meaning that all standards of care measured by the questions were met. The Index score was composed of each domain score average, equally weighted.

The use of the Index score and of the independent domain scores provided an analytical framework which allowed the comparison of different units of analysis: camps, governorates, and type of supporting organisation (NGO, INGO, Department of Health) using averages per unit of analysis.

Population and base camp data were reported, then Index and domain scores were provided by Governorate and type of organisation. Phase 1 (June 2018) results were analysed $(n=55)$ and the different scores for the Governorate and type of supporting organisation were assessed. Then Phase 2 ( $n=47$, December 2018) was compared to Phase 1 , with a focus on the same camps between phases $(\mathrm{n}=46)$. The third step considered all camps between the two phases $(n=102)$, specifically looking at the domain contribution to the Index Score through linear regressions, $\mathrm{R}^{2}$ and $p$ values were reported. Furthermore, the relationship between camp size (IDP count) and index scores was evaluated. Statistical analyses (T-test) were conducted to compare means between phases and assess the significance when appropriate.

\section{Results}

\section{Population data, camp characteristics}

In Phase 1 , there were 535,253 individuals spread over 55 camps, distributed in 89,235 families with an average of 6 members per family. The 55 camps were spread over 20 districts located in 8 governorates. On average, $51 \%$ of the individuals were females. The governorate of Ninewa 
Table 2 Summary table of average index score and domains by (a) governorate and (b) type of supporting organization

\begin{tabular}{|c|c|c|c|c|c|c|c|c|}
\hline & \multicolumn{2}{|c|}{ IDP COUNT } & \multicolumn{2}{|c|}{ \# CAMPS } & \multicolumn{2}{|c|}{ Index score (\%) } & \multicolumn{2}{|c|}{$\begin{array}{l}\text { Environment and safety } \\
\text { (\%) }\end{array}$} \\
\hline & Phase 1 & Phase 2 & Phase 1 & Phase 2 & Phase 1 & Phase 2 & Phase 1 & Phase 2 \\
\hline \multicolumn{9}{|l|}{ (a) Governorate } \\
\hline Anbar & 38,465 & 27,546 & 6 & 3 & 53.1 & 80.2 & 53.7 & 79.6 \\
\hline Dahuk & 151,896 & 152,136 & 11 & 11 & 57.4 & 58.3 & 66.7 & 62.1 \\
\hline Diyala & 7332 & 4068 & 3 & 1 & 64.8 & 43.1 & 87.0 & 77.8 \\
\hline Erbil & 19,062 & 10,488 & 4 & 1 & 50.6 & 72.4 & 47.2 & 66.7 \\
\hline Kirkuk & 17,898 & 13,278 & 5 & 4 & 57.1 & 62.3 & 64.4 & 80.6 \\
\hline Ninewa & 275,802 & 278,322 & 19 & 19 & 54.7 & 69.8 & 61.1 & 75.7 \\
\hline Salah al-Din & 4782 & 7506 & 2 & 3 & 57.5 & 56.2 & 72.2 & 79.6 \\
\hline Sulaymaniyah & 20,016 & 20,634 & 5 & 5 & 51.8 & 64.7 & 60.0 & 73.3 \\
\hline Average & & & & & 55.9 & 65.2 & 64.1 & 74.4 \\
\hline Total & 535,253 & 513,978 & 55 & 47 & & & & \\
\hline \multicolumn{9}{|c|}{$\begin{array}{l}\text { (b) Type of supporting } \\
\text { organisation }\end{array}$} \\
\hline $\mathrm{DOH}$ & 24,360 & 41,430 & 9 & 7 & 61.7 & 63.7 & 71.6 & 79.4 \\
\hline INGO & 169,500 & 75,180 & 22 & 9 & 52.1 & 74.3 & 54.0 & 88.9 \\
\hline NGO & 341,393 & 397,368 & 24 & 31 & 55.9 & 62.9 & 66.7 & 67.0 \\
\hline Average & & & & & 55.9 & 65.2 & 64.1 & 74.4 \\
\hline \multirow[t]{3}{*}{ Total } & 535,253 & 513,978 & 55 & 47 & & & & \\
\hline & \multicolumn{2}{|c|}{ Client care (\%) } & \multicolumn{2}{|c|}{ Technical competence (\%) } & \multicolumn{2}{|c|}{ Management (\%) } & \multicolumn{2}{|c|}{ Satisfaction (\%) } \\
\hline & Phase 1 & Phase 2 & Phase 1 & Phase 2 & Phase 1 & Phase 2 & Phase 1 & Phase 2 \\
\hline \multicolumn{9}{|l|}{ (a) Governorate } \\
\hline Anbar & 48.6 & 79.0 & 51.5 & 65.2 & 47.9 & 83.6 & 63.8 & 93.8 \\
\hline Dahuk & 59.6 & 47.4 & 50.4 & 50.4 & 53.1 & 64.6 & 57.0 & 66.8 \\
\hline Diyala & 59.5 & 21.4 & 50.0 & 9.1 & 55.2 & 49.1 & 72.2 & 58.3 \\
\hline Erbil & 53.9 & 75.0 & 54.5 & 86.4 & 38.2 & 70.4 & 59.1 & 63.7 \\
\hline Kirkuk & 60.5 & 62.8 & 44.5 & 59.1 & 52.3 & 41.4 & 63.7 & 67.7 \\
\hline Ninewa & 53.8 & 71.3 & 49.5 & 72.5 & 50.5 & 61.4 & 58.5 & 68.1 \\
\hline Salah al-Din & 51.8 & 55.6 & 61.4 & 62.1 & 53.2 & 38.0 & 49.1 & 45.8 \\
\hline Sulaymaniyah & 47.6 & 66.0 & 42.7 & 57.3 & 51.9 & 61.3 & 56.7 & 65.6 \\
\hline Average & 54.4 & 59.8 & 50.6 & 57.7 & 50.3 & 58.7 & 60.0 & 66.2 \\
\hline \multicolumn{9}{|c|}{$\begin{array}{l}\text { (b) Type of supporting } \\
\text { organisation }\end{array}$} \\
\hline $\mathrm{DOH}$ & 61.9 & 62.2 & 52.0 & 54.5 & 55.9 & 51.2 & 67.3 & 71.3 \\
\hline INGO & 51.0 & 79.6 & 50.8 & 80.3 & 48.2 & 60.2 & 56.6 & 62.4 \\
\hline NGO & 55.4 & 58.2 & 47.7 & 58.9 & 50.6 & 62.4 & 59.3 & 68.0 \\
\hline Average & 54.4 & 59.8 & 50.6 & 57.7 & 50.3 & 58.7 & 60.0 & 66.2 \\
\hline
\end{tabular}

contained most camps $(\mathrm{n}=19)$, followed by Dahuk $(\mathrm{n}=16)$. Together these two governorates accounted for almost $80 \%$ of the IDP population located in camps. Ninewa alone accounted for $52 \%$, with the biggest camp having more than 44,000 individuals (Qayyarah Airstrip) in the governorate. The smallest camp was located in the governorate of Sulayamniyah, (174 individuals).
The median camp population was 5910 individuals. Out of the 55 camps, 24 PHCCs were run by NGOs, 22 by international NGOs (INGO), and 9 by the Directorate of Health (DOH). INGOs supported 169,500 IDPs, i.e., 31\% of the total IDP population in camps, NGOs supported 341,391 IDPs. In Phase 2, 47 camps were operational, the total number of individuals was 513,978 (85,633 families), 


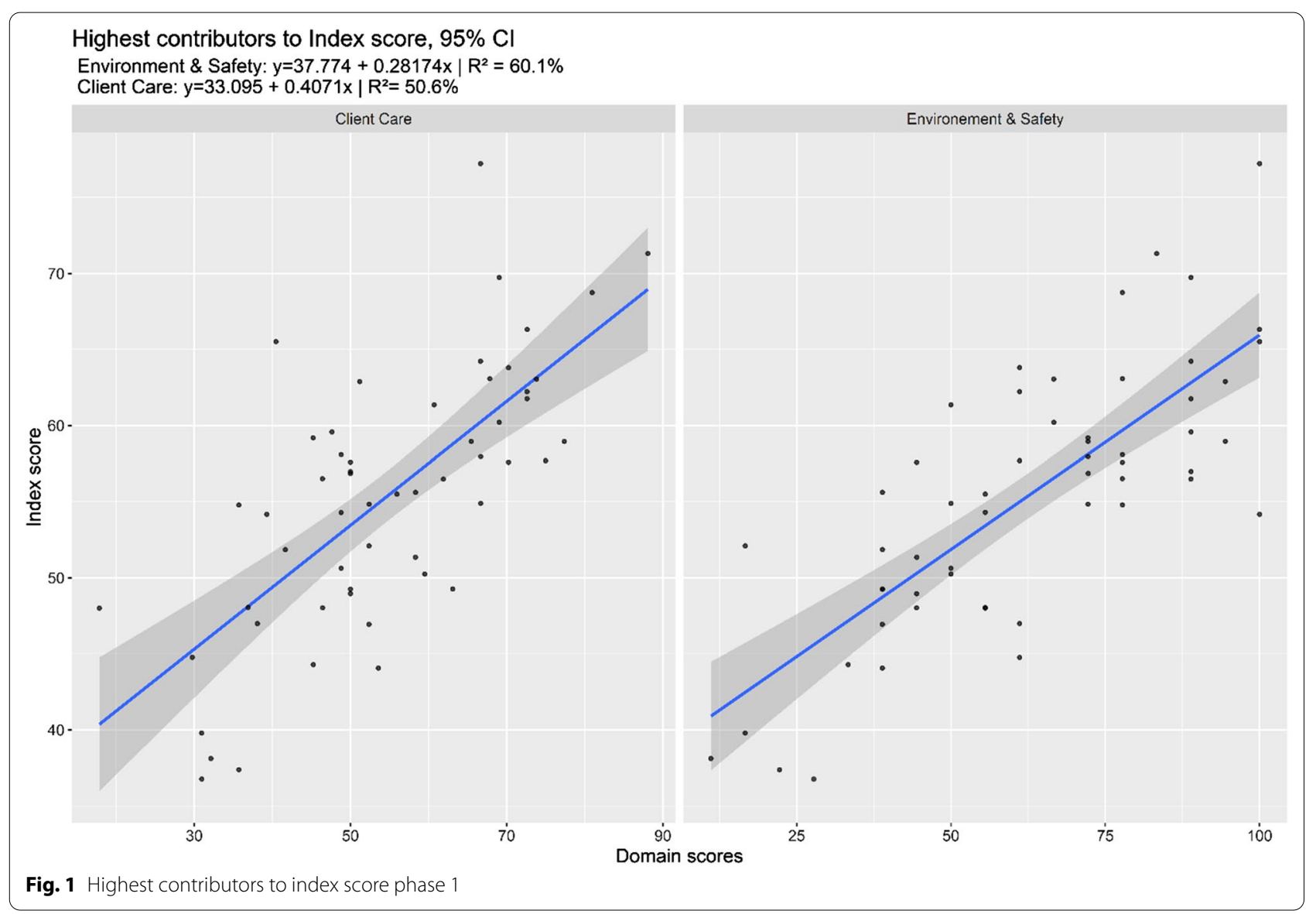

$51 \%$ females, with median camp size of 8826 individuals. The governorate of Ninewa and Qayyarah Airstrip were still the most populous.

\section{Governorate and type of supporting organisation results}

A summary table (Table 2) describes all domains and Index score by governorate, by type of supporting organisation, and phases.

\section{Phase 1}

In Phase 1 at camp level, the average Index score was $55.9 \%$, with the lowest camp scoring $36.7 \%$ and the highest $77.2 \%$. The lowest score was recorded in the governorate of Sulaymaniyah, where the facility was supported by an INGO, 15 percentage points lower than the governorate average. The highest scoring camp was found in the governorate of Dahuk, supported by an INGO.

At the governorate level, the Governorate of Diyala scored the highest on the overall average performance (Index Score $=65 \%$ ) and Erbil the lowest with 50.6\%.
Diyala hosted three camps, and all the PHCC were supported by the DoH. In Erbil, there were four camps, all these PHCC in the camps received INGO support.

According to Phase 1 composite scores, health facilities supported by INGOs provided the lowest overall quality of care with an average of $52.1 \%$ on the Index score, and scored the lowest on all domains, except Technical Competence when compared to the Directorate of Health or NGOs. However, the differences between INGOs and other providers was not significant $(p>0.1)$.

In Phase 1, the Client Care (CC) and Environment and Safety (ES) domains contributed most to the Index Score, as shown in Fig. 1. The ES domain accounted for $60.1 \%$ and Client Care for $50.6 \%$ of the variation in the overall Index score $(p<0.001)$. Both related mostly to observational aspects as they were only measured by facility and consultation observations. Management explains about 22.7\%, Technical Competence 19.3\% (both significant at $p<0.01$ ), but Satisfaction was not significant and only explained $6.8 \%$ of the variance. 


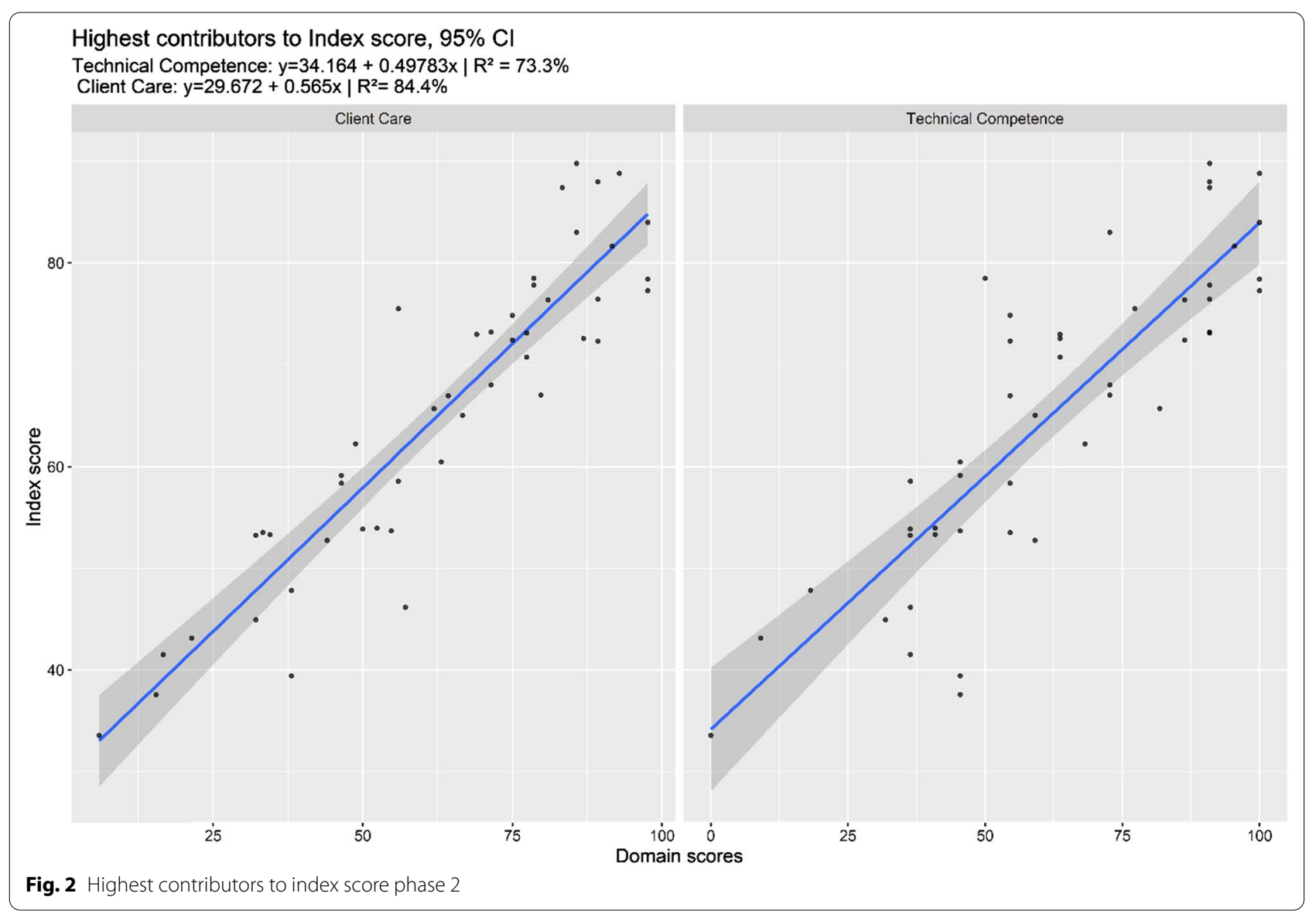

\section{Comparison phase 1-phase 2}

In Phase 2, the average Index score was $65.2 \%$, with a maximum of $89.8 \%$ and a minimum of $33.6 \%$. For all camps $(n=102)$, the overall average index score had increased between the two phases by 10 points. The highest-scoring camp was located in the governorate of Ninewa, supported by an NGO. The lowest scoring camp was in the governorate of Dahuk, which was also supported by an NGO. The camp scored $0 \%$ on Technical competence and $6 \%$ on Client care. Compared to Phase 1 , the highest scoring camp scored 12 percentage points higher, with more than 8s000 IDPs. The profile of the lowest-scoring camp in phase 2 was very different of that from Phase 1: the number of IDPs was 24 times bigger than the lowest-scoring in Phase 1. The lowest-scoring camp of phase 1 had been consolidated into another camp. The highest-scoring in Phase 1 scored 70.7\% in Phase 2, a decline of $10 \%$. All implementing partners increased their index score between the two phases, with the highest increase for INGO from 52 to $74 \%$, changing it from the lowest-scoring in Phase 1 to the highest-scoring in Phase 2.
Alongside, the contributions of the different domains to the Index Score also changed compared to Phase 1. As shown in Fig. 2, Technical Competence $\left(R^{2}=60.1 \%\right)$ and Client Care $\left(\mathrm{R}^{2}=50.6 \%\right)$ explained most of the variation in the Index Score $(p<0.001)$, and from a visual inspection, the dispersion was also lower than in Phase 1 . The fact that the dispersion was lower could indicate that overall quality of care was being standardized and, therefore, that, on average, the camps were reaching the same standards of care as measured by the different domains. The analysis also showed that the satisfaction of patients increased and remained high from phase 1 to phase 2 .

\section{Differences between camps in phase 1 and phase 2}

Out of the 55 camps in Phase 1, 46 remained open and functional in Phase 2, and there was one new camp (Salah al-Din Tikrit, Al-Alam Camp 1) in Phase 2. Table 2a and b show variations in the Index Score and the domains. The Governorate of Anbar showed the highest increase in scores with an average 30.6 percentage point increase for the three camps that remained open. On the other hand, Diyala, which lost two of its three camps from 
Table 3 Point difference between phase 1 and phase 2

\begin{tabular}{|c|c|c|c|c|c|c|c|c|}
\hline \multirow[t]{2}{*}{ Governorate } & & \multicolumn{7}{|c|}{ Point difference between phase 1 and phase 2 (phase 2-phase 1) } \\
\hline & & $\begin{array}{l}\text { \# Camps } \\
\text { difference }\end{array}$ & Index score & $\begin{array}{l}\text { Environment } \\
\text { and safety }\end{array}$ & Client Care & $\begin{array}{l}\text { Technical } \\
\text { competence }\end{array}$ & Management & Satisfaction \\
\hline Anbar & & -3 & 27.1 & 25.9 & 30.4 & 13.7 & 35.7 & 30 \\
\hline Dahuk & & 0 & 0.9 & -4.6 & -12.2 & 0 & 11.5 & 9.8 \\
\hline Diyala & & -2 & -21.7 & -9.2 & -38.1 & -40.9 & -6.1 & -13.9 \\
\hline Erbil & & -3 & 21.8 & 19.5 & 21.1 & 31.9 & 32.2 & 4.6 \\
\hline Kirkuk & & -1 & 5.2 & 16.2 & 2.3 & 14.6 & -10.9 & 4 \\
\hline Ninewa & & 0 & 15.1 & 14.6 & 17.5 & 23 & 10.9 & 9.6 \\
\hline Salah al-Din & & 1 & -1.3 & 7.4 & 3.8 & 0.7 & -15.2 & -3.3 \\
\hline \multirow[t]{7}{*}{ Sulaymaniyah } & & 0 & 12.9 & 13.3 & 18.4 & 14.6 & 9.4 & 8.9 \\
\hline & Average & & 7.5 & 10.4 & 5.4 & 7.2 & 8.4 & 6.21 \\
\hline & Type of supporting organisation & & & & & & & \\
\hline & $\mathrm{DOH}$ & -2 & 2.0 & 7.8 & 0.3 & 2.5 & -4.7 & 4 \\
\hline & INGO & -13 & 22.2 & 34.9 & 28.6 & 29.5 & 12 & 5.8 \\
\hline & NGO & 7 & 7.0 & 0.3 & 2.8 & 11.2 & 11.8 & 8.7 \\
\hline & Average & & 10.4 & 14.3 & 10.6 & 14.4 & 23.5 & 6.4 \\
\hline
\end{tabular}

Phase 1 , the Index score decreased by an average of 20 percentage points. The highest increase in domain score was in Satisfaction with a 41.7 percentage point increase in the Governorate of Erbil. Of the governorates that did not see any change in camp numbers (Dahuk, Ninewa, Sulaymaniyah), all scores increased.

In terms of the type of organisation in Phase 2, a large number of INGOs were not handling camps anymore (13 camps fewer) while NGOs took on 7 more camps. In general, the different domains, as well as the index score, increased by more percentage points for INGOs than for NGOs. In concordance to both Phase 1 and Phase 2 for all camps, the main contributing domain to the index score and the index score difference remained 'Client Care' ( $\left.\mathrm{r}^{2}=81 \%\right)$, followed by 'Environment \& Safety' and 'Technical Competence' $\left(r^{2}=65 \%\right.$ and $64.1 \%$ ) all significant at $p>0.001$. The differences between Phase 1 and Phase 2 are shown in Table 3.

\section{Contribution to index score, camp size, and distribution of scores}

In general, when looking at all camps in both Phase 1 and Phase $2(n=102)$ and comparing which domain contributed most to the total score, 'Client Care' contributed most and with very little dispersion. On the other hand, 'Management and Satisfaction' seemed to be the least informative for the Index score (Fig. 3).

Patient satisfaction and camp size were also positively correlated but not significant $\left(\mathrm{r}^{2}=2.4 \%, p>0.1\right)$. A potential reason to explain such a pattern is that as the camp grows, more resources are mobilized. At the time of data collection, the camps and health facilities had already been running for some years, therefore, it is possible that issues were previously resolved. The same relation was observed between camp size and the other domain scores, yet the 'Satisfaction' score seemed unrelated to all other domains.

A critical question regarding camps, in general, was whether the number of people per camp impacted the quality of care delivered, as the number of care providers and facilities were only increased by a small amount. As shown in Fig. 4, there was a very slight slope between the overall quality of care and the number of individuals in camps. However, if when removing the two outlying points (not shown; Qayyarah Airstrip Camp Phase 1 and 2 ), the relation became flat. We expected no further relation between the number of individuals and the quality of care provided.

\section{Discussion}

This study was one of the first to evaluate the quality of care provided to IDPs in camps in emergency settings and we observed that the provision of quality care is correlated to the patient's experience as well as environmental and safety factors. We also observed that the size of the camp or the type of organisation were not related to the measurement of quality of care. Below is discussed how governorate and type of organisation specificities may explain variances in results. The second part enquires about the type of indicators used here, as well 


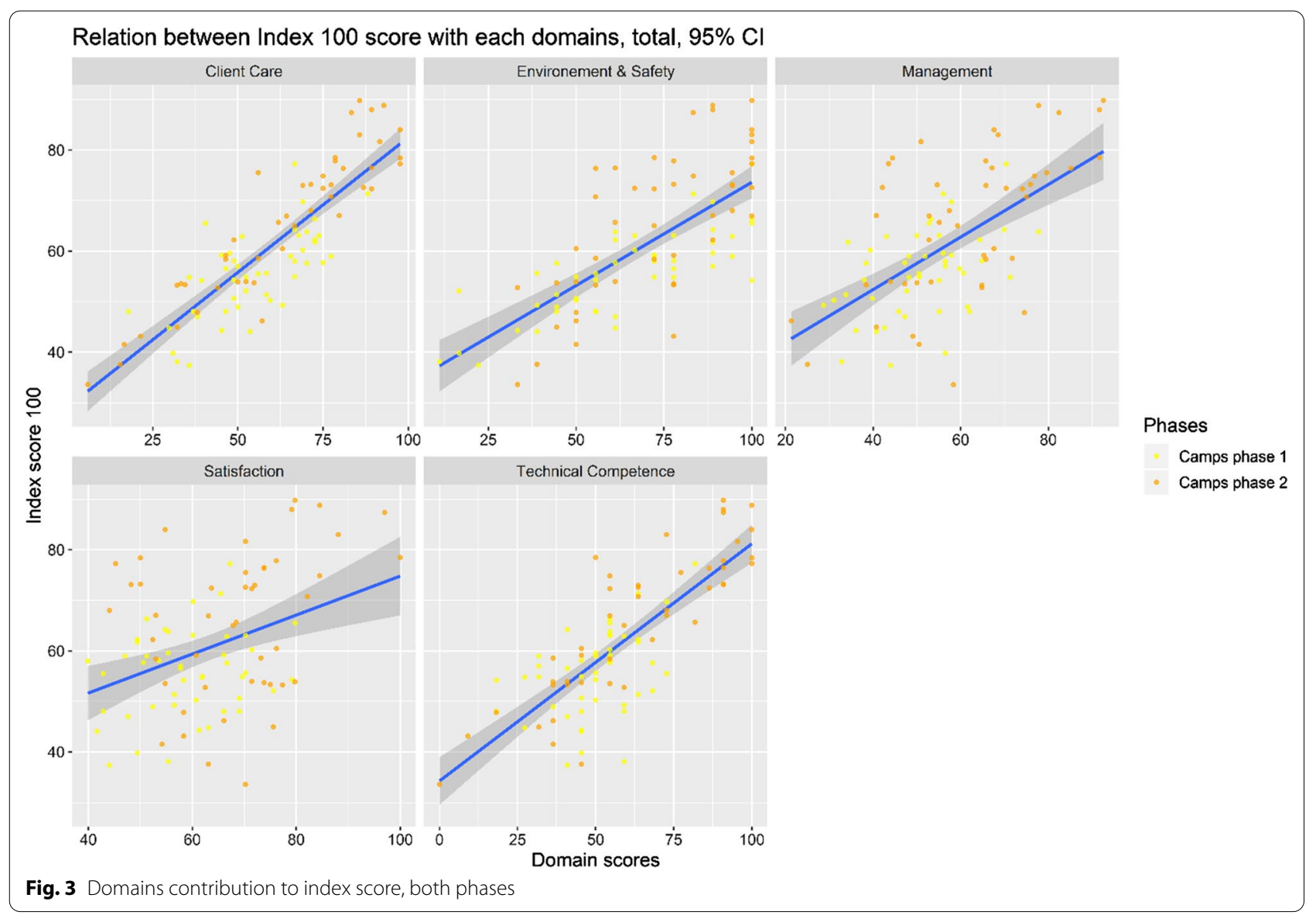

as their interactions. Finally, the situation of quality of care in the Iraqi context and humanitarian settings are touched upon.

\section{Governorate and type of organisation performance}

The differences in scores between governorates could be partially explained by the distribution of IDPs, the oversight by the respective $\mathrm{DoH}$, and the number and capacity of partners (NGOs, INGOs). On average, the governorates of Ninewa and Dahuk were performing well in regard to the number of IDPs they have. It was worth noting that governorates with the lowest number of IDPs were the only two governorates for which the Index score dropped between Phase 1 and Phase 2. This could be attributed to access and security related issues, local capacity, as well asthe willingness of the DoH to oversee the quality of care in these camps.

INGOs, the lowest-scoring type of organisation in Phase 1, became the highest-scoring in Phase 2, apparently being the best able at incorporating the findings from Phase 1 into Phase 2 to improve the quality of care.
According to respondents, local NGOs addressed most patients needs in both phases. However, while they outperformed other types of organisations in Phase 1, they became the lowest-performing in Phase 2.

\section{Scores, index, and their interactions}

Out of both phases and for all camps, 'Client care' and 'Environment and Safety' appeared to be the most important domains contributing to the general qualityof-care score. Interestingly, direct satisfaction measurement showed little contribution and no significance to the Index Score. Some domains did not include questions measuring the same issues between interviews and observations due to design constraints. 'Environment and Safety' measure basic amenities (e.g., provision of water or clean toilets) for clients. Similarly, 'Technical Competence' was also measured mostly through observation. Finally, the domain contributing most, 'Client Care', collected observation pertaining to the patients' experiences (see Additional file 1). It could imply that the experience of the patient in terms of quality in the facility and the 


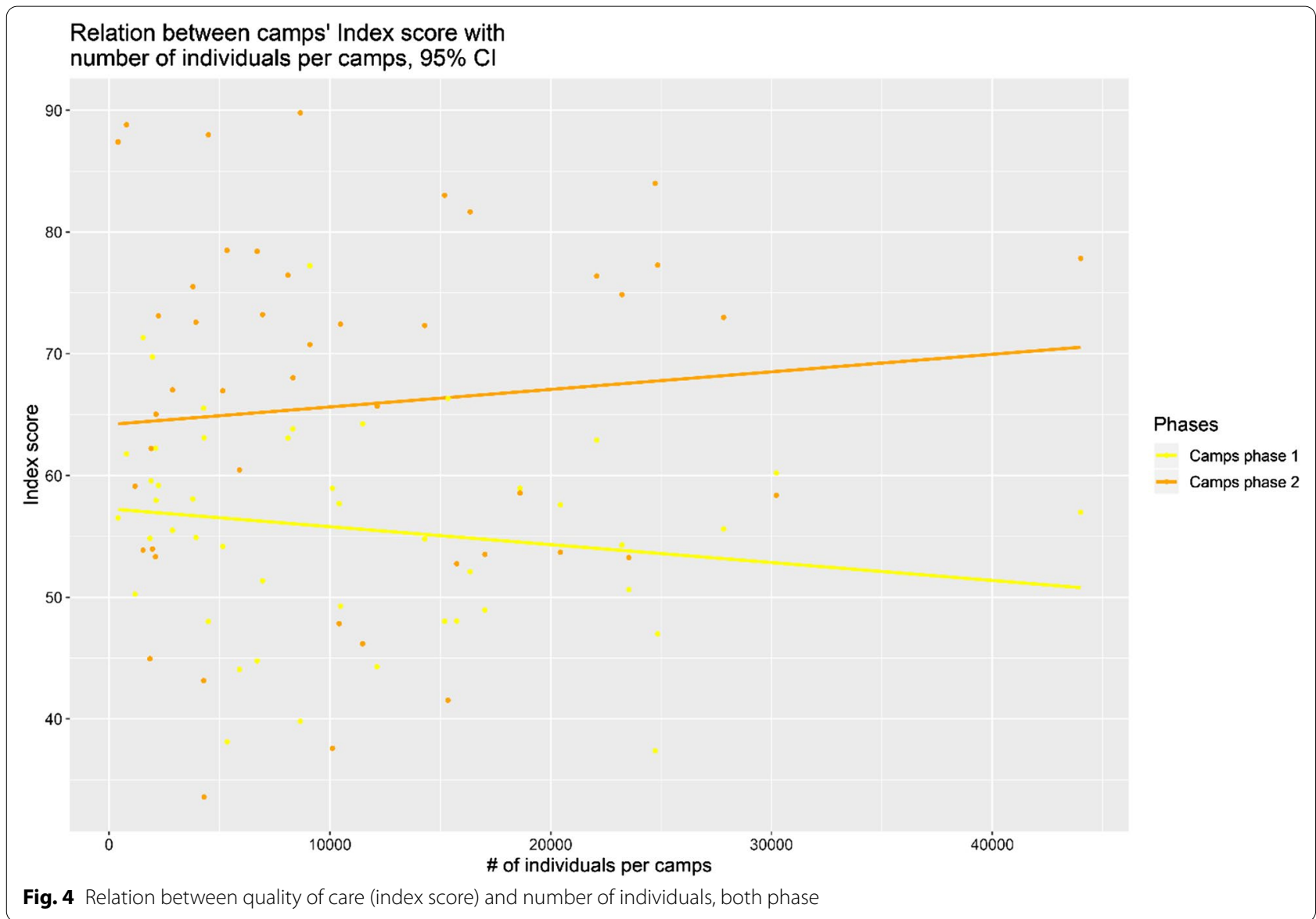

feeling of being properly taken care of by the provider are crucial in providing quality of care. The literature in this regard, seemed to mostly corroborate this finding [27, 50-52], however, it cannot be fully answered here.

The lower dispersion of Client Care and Technical competencies scores seen in Fig. 2 could indicate that overall quality of care was being standardized and, therefore, that, on average, the camps were reaching the same standards of care as measured by the different domains. The analysis also showed that the satisfaction of patients increased and remained high from Phase 1 to Phase 2. The construction of the 'Satisfaction' domain was conceptually difficult, and the selection of questions composing the domain may explain why it did not relate to any score. Conceptual and theoretical issues relating to the scores were partially explained by the fact it was an operational research with the primary purpose to inform and improve quality-of-care delivery in PHCC. Additionally, the specific context may have led IDP not to be critical of the services received, skewing the results. In fact, the war in Iraq in 2003 and its long-term consequences severely weakened the health system [27, 50-56]. More broadly, a current debate in emergency setting camps is that people inside camps have access to better services than people outside camps $[3,11,25,56,57]$. That can largely influence the perceived quality of care, and therefore the satisfaction of patients.

Quality of care remains an unexplored domain in emergency settings [4], where the SPHERE standards are widely used and only provide basic minimum criteria $[20,34,58]$. As many crises are lasting longer, the importance of assessing the quality of care becomes essential and this research shows that it is possible to measure the quality of care to IDPs beyond emergency standards. Insights from this short assessment have already been used by the Health Cluster to inform the health partners operating in camps and improve quality in PHCCs.

\section{Limitations}

As a rapid general assessment of the quality of care, some questions and observations that could bring extra critical information have been left out to reduce the data collection time. First, the conceptual and operational definitions of quality of care were chosen for 
pragmatic and contextual reasons relating to the emergency of situation, the need for a rapid assessment, and to the cultural and economic proximity between the Jordanian and Iraqi contexts. Other definitions could have provided different insights. Second, while patients declared in general to be satisfied with the services, no questions about the waiting time of patients, often a critical factor in quality [59-61], was asked. More broadly, 'people centeredness', part of the WHO QoC definition, could not be adequately assessed here. The selected observation and interview questions from tested tools were the most critical to measure the quality of care in camps in relation to the non-emergency standard for the minimum package of Primary Health Care services delivered in camp settings. Despite that limitation, it provided a rapid assessment fitting emergency and sensitive contexts in which rapid evidence generation is crucial. Third, some parts of the tools were from a manual written in 2004 and were pretested locally and adjusted afterwards. However, during the analysis, some questions appeared ambiguous on the answers possible, asking for different items within the same question. Potential confounders could not be collected nor tested to limit risks and disturbance on health care provision. This has implication for the validity of the statistical results. Data collectors were trained to ensure the quality of the data, but observation bias, especially for technical competence, were expected and mitigated by having medically qualified enumerators. Other limitations were specific to the setting. The 'Satisfaction' domain score was not considered very informative based on its composition, however, it can be improved and better measured in subsequent research. Previous experience and knowledge of current IDPs about health care, prior to the emergency, is unknown and, therefore, their expectation cannot be explored, nor their satisfaction level fully understood. Finally, although it is meant to be a rapid assessment of the quality of care taking place in a difficult context, the representation of the beneficiaries cannot be verified with six respondents per health facility. Correcting for such limitations was attempted using observations and a checklist to assess perceived and realised quality of care.

\section{Conclusion}

This analysis of the quality of care provided in PHCC in IDP camps in Iraq in 2018 in a humanitarian emergency setting shed some light on both the quality of care in camps, and on the method of such assessment. This research attempted to demonstrate that it is possible to measure the quality of care beyond SPHERE standards. It is an important step toward ensuring that IDPs' dignity is respected by providing them with adequate and quality care. Further research is necessary on both the way to provide such quality of care, as well as to assess it in an emergency context. Nonetheless, such research remains very relevant as most emergencies are long, protracted crises where morbidity reduction rather than mortality reduction becomes the focus of care provision. An essential aspect of the overall quality of care provided in PHCCs is the involvement of the Iraqi government through the DoH. This was possible as only parts of the country suffered from a heavy disruption of services, while the integrity of state authority was maintained. This point is important as many emergencies are localized and governmental function and integrity remain, at least partially, in most contexts. In Iraq, the cooperation between the DoH, international NGO's, and local NGOs allowed the delivery of primary health care to vulnerable populations, and the possibility to improve the quality of care delivered to IDP camps.

A few recommendations can be extracted from this assessment. Firstly, regular quality-of-care assessments are necessary and need to be thought through, planned, and carried out from the onset of the emergency response by the different cluster leads. Data from these assessments need to be shared immediately with the stakeholders involved to ensure improvement processes take place. Secondly, the cooperation of all implementing partners through the Health Cluster allowed for an overall improvement in the quality of care delivered, and this reinforces the necessity to include all stakeholders in emergency responses [56, 62-64]. Thirdly, this study can help humanitarian organisation, implementing partners, and governments to improve the quality of primary health care delivery in camp settings, both in emergency and post-emergency contexts. Finally, it shows that it is possible to improve the quality of care for beneficiaries beyond the minimum SPHERE standards.

This study provides an important step towards improving the quality of care in camps in Iraq and elsewhere by showing it is possible to assess the quality of care through standardized, non-emergency quality care criteria in emergency settings and can help set up such assessments in similar settings with the hope of providing better and ever-improving health services to displaced people.

\section{Appendix} Appendix 1 Fig. 5

See Fig. 5. 

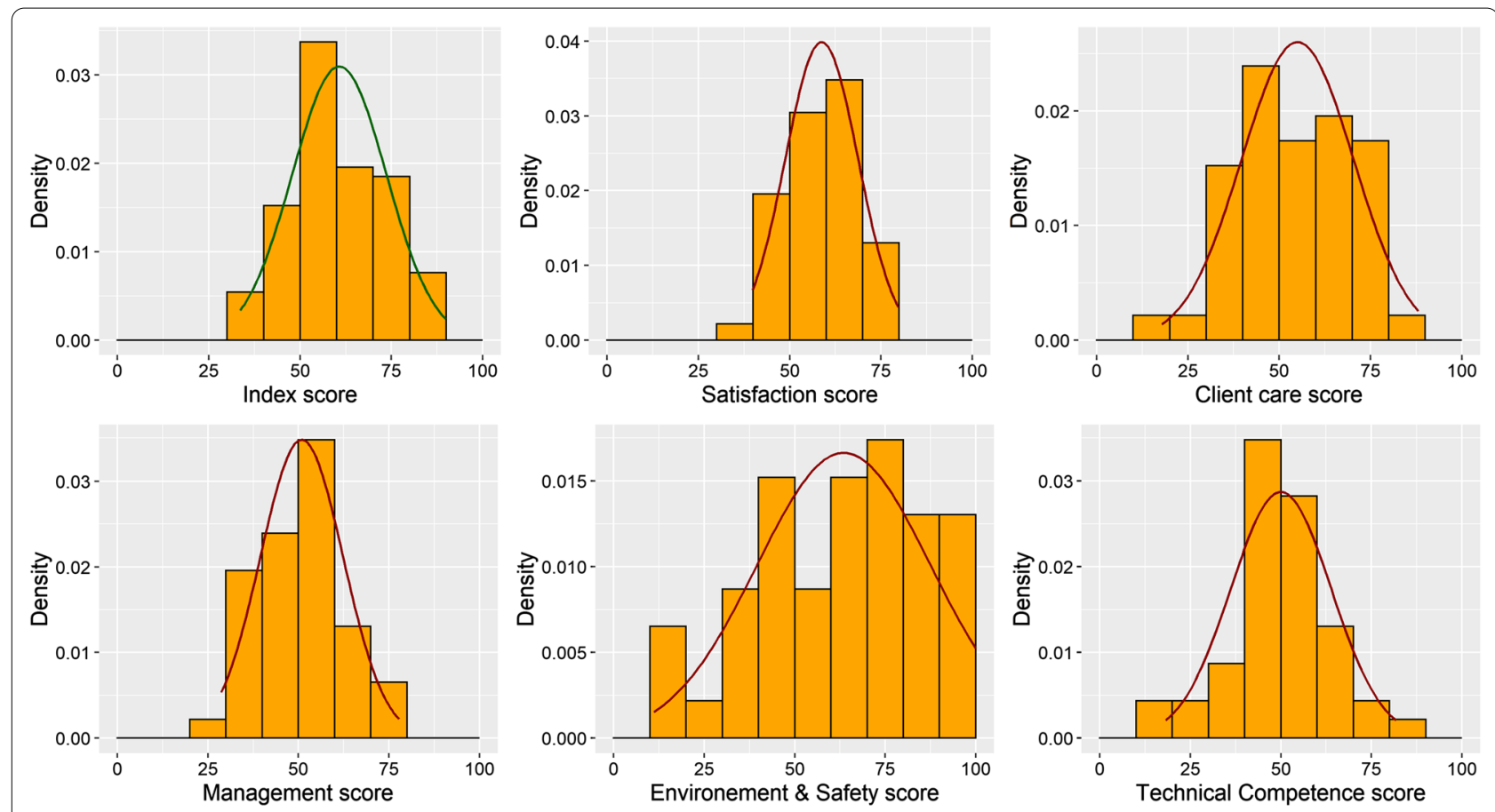

Fig. 5 Distribution of index and domains scores, all camps, both phases

\section{Appendix 2: Definitions \\ IDP and camps}

The definition of Internally Displaced Person is the following: Persons or groups of persons who have been forced or obliged to flee or to leave their homes or places of habitual residence, in particular as a result of or in order to avoid the effects of armed conflict, situations of generalized violence, violations of human rights or natural or human-made disasters, and who have not crossed an internationally recognized state border. Camps are usually understood as temporary and last resort solutions that offer protection and assistance for population who have been displaced from their homes because of violence, nature- or human-made disasters $[44,65]$.

\section{Health cluster partners}

The Health Cluster partners are the supporting organisations and comprise local NGO (NGOs), international NGOs (INGO), and the Directorate of Health, subdivision of the Ministry of Health at the Governorate level.

\section{WHO quality of care}

- Effective: delivering health care that is adherent to an evidence base and results in improved health outcomes for individuals and communities, based on need.
- Efficient: delivering health care in a manner which maximizes resource use and avoids waste; accessible, delivering health care that is timely, geographically reasonable, and provided in a setting where skills and resources are appropriate to medical need.

- Acceptable/patient-centered: delivering health care which takes into account the preferences and aspirations of individual service users and the cultures of their communities

- Equitable, delivering health care which does not vary in quality because of personal characteristics such as gender, race, ethnicity, geographical location, or socioeconomic status.

- Safe, delivering health care which minimizes risks and harm to service users.

\section{Abbreviations}

CC: Client care; CCCM: Camp coordination and camp management; DoH: Directorate of health; ES: Environment and safety; IASC: Inter-agency standing committee; IDP: Internally displaced persons; I/NGO: International/Nongovernmental Organisation; IOM: International office for migration; IRCS: Iraqi Red Crescent Society; MG: Management; PHCC: Primary health care centre; ST: Satisfaction; TC: Technical competence; UNHCR: United Nations high commissioner for refugees; WASH: Water, sanitation and hygiene. 


\section{Supplementary Information}

The online version contains supplementary material available at https://doi. org/10.1186/s13031-021-00402-4.

Additional file 1. Data collection tools: Facility observation, Clinical Observation, Health worker interview, Patient exit interview.

\section{Acknowledgements}

Phase 1: Dr Manhal Alhalasa, Dr Mikiko Senga, Denise Assaf, Karol Vaness Ramirez, Adela Humood Alaboudi (Ex Minister Health - Iraq). Phase 2: Mohammad Ereiqat, Dr Alaa Abdessaheb al-Alwan (Minister of Health -Iraq). Both Phases 1-2: Abdul Rahman, Amar Nore

\section{Authors' contributions}

MFK conceived the study, coordinated data collection, revised drafts, and provided contextual information. DJ performed the data and overall analysis and wrote the drafts. KSO reviewed drafts and provided contextual information of the survey and corrections to the analysis. ASM and ARIAM contributed to the conception and data collection. $\mathrm{WH}$ revised the work. $\mathrm{MB}$ and $\mathrm{PZ}$ supported data and overall analysis, reviewed all drafts, and provided recommendations on the way forward. All authors read and approved the final manuscript.

\section{Funding}

The Office of U.S. Foreign Disaster Assistance (OFDA) funded 100\% of this study.

\section{Availability of data and materials}

Data were collected by WHO for the health cluster for the camps in Iraq, which was later presented to Iraqi Ministry of Health, partners, and donors for monitoring. Data is available upon reasonable request at the WHO Country Office Iraq.

\section{Declarations}

\section{Ethics approval and consent to participate}

The quality-of-care survey was thoroughly discussed in the health cluster meetings, in which the Ministry of Health took part. In Iraq, health cluster meeting minutes at national and sub-national levels are considered officia documents by the Ministry of Health. The minutes of cluster meetings held in Baghdad (17th April 2018) and Erbil (2nd May 2018) were endorsed by the Ministry of Health. All people interviewed provided verbal consent before the start of the interview.

\section{Consent for publication}

WHO as well as the Ministry of Health provided consent for publication. No individual patient or health worker data is provided, therefor individual consent for publication was not needed.

\section{Competing interests}

The process of analysis was shared with the concerned partners and DoHs periodically; none of the partners have any objections; they are used this data as a baseline to either improve or sustain its quality-of-service provision.

\section{Author details}

${ }^{1}$ WHO Country Office - Iraq, Baghdad, Iraq. ${ }^{2}$ Erasmus Medical Centre, Rotterdam, The Netherlands. ${ }^{3}$ KIT Royal Tropical Institute, Amsterdam, The Netherlands.

Received: 6 August 2019 Accepted: 23 August 2021

Published online: 08 September 2021

\footnotetext{
References

1. UN Ocha. Humanitarian needs overview 2019: Iraq. Geneva: UN Ocha 2018.

2. (IOM) I for M. Iraq displacement crisis 2014-2017. Geneva: IOM; 2018.
}

3. The World Bank Group. Iraq reconstruction and investment assessment Washington DC: The World Bank; 2018.

4. Jordan K, Lewis TP, Roberts B. Quality in crisis: a systematic review of the quality of health systems in humanitarian settings, vol. 15. Conflict and health. London: BioMed Central Ltd.: 2021.

5. Vu A, Wirtz AL, Bundgaard S, Nair A, Luttah G, Ngugi S, et al. Feasibility and acceptability of a universal screening and referral protocol for genderbased violence with women seeking care in health clinics in Dadaab refugee camps in Kenya. Glob Ment Health. 2017:4:E21.

6. Lassi ZS, Aftab W, Ariff S, Kumar R, Hussain I, Musavi NB, et al. Impact of service provision platforms on maternal and newborn health in conflict areas and their acceptability in Pakistan: a systematic review, vol. 9. Conflict and health. London: BioMed Central Ltd.; 2015.

7. Alduraidi $\mathrm{H}$, Waters $\mathrm{CM}$. Health-related quality of life of Palestinian refugees inside and outside camps in Jordan. Nurs Outlook. 2017:65(4):436-43.

8. Garry S, Checchi F, Cislaghi B. What influenced provision of noncommunicable disease healthcare in the Syrian conflict, from policy to implementation? A qualitative study 11 Medical and Health Sciences 1117 Public Health and Health Services Bayard Roberts, Kiran Jobunputra, Preeti Patel and Pablo Perel. Confl Health. 2018;12(1):1-10.

9. Orach CG, Aporomon JF, Musoba N, Micheal L. Accessibility and availability of health care services to internally displaced persons, in Kitgum and Pader districts, northern Uganda. Health. 2013;05(09):1433-42.

10. Kersten R, Do F, Slavuckij A, Fernandez G, Marx M. Too complicated for the field? Meas Qual Care Humanit Aid Settings. 2013;1:1-7.

11. Wanzira H, Muyinda R, Lochoro P, Putoto G, Segafredo G, Wamani H, et al. Quality of care for children with acute malnutrition at health center level in Uganda: a cross sectional study in West Nile region during the refugee crisis. BMC Health Serv Res. 2018;18(1):1-10.

12. Spiegel PB, Checchi F, Colombo S, Paik E. Health-care needs of people affected by conflict: future trends and changing frameworks. Lancet. 2010;375(9711):341-5.

13. Thomas SL, Thomas SDM. Displacement and health. Br Med Bull. 2004;69:115-27.

14. Sahlool Z, Sankri-Tarbichi A, Kherallah M. Evaluation report of health care services at the Syrian refugee camps in Turkey. Avicenna J Med. 2012;2(2):25.

15. Pacheco-Coral AP. Statelessness, exodus, and health: forced internal displacement and health services. Cad Saúde Pública. 2018. https://doi. org/10.1590/0102-311×00027518

16. Cetorelli V, Burnham G, Shabila N. Health needs and care seeking behaviours of Yazidis and other minority groups displaced by ISIS into the Kurdistan Region of Iraq. PLoS ONE. 2017:12(8):e0181028.

17. Sphere Association. The Sphere handbook: humanitarian charter and minimum standards in humanitarian response. Vol. 1, Response. 2018

18. World Health Organization (WHO). Quality of care: a process for making strategic choices in health systems. Geneva: World Health Organization; 2006

19. UNHCR the UN Refugee Agency. Global Strategy for Public Health. Geneva: UNHCR the UN Refugee Agency; 2014.

20. Waldman RJ, Toole MJ. Where is the science in humanitarian health? Lancet. 2017:390(10109):2224-6.

21. Blanchet K, Frison S, Smith J. Review of the evidence supporting the SPHERE standards. London: R2HC-Elrh; 2017.

22. Aziz IA, Hutchinson CV, Maltby J. Quality of life of Syrian refugees living in camps in the Kurdistan Region of Iraq. PeerJ. 2014;2:e670.

23. De Vries J, Van Heck GL. Quality of life and refugees. Int J Ment Health. 2015;23(3):57-75.

24. Benner MT, Townsend J, Kaloi W, Htwe K, Naranichakul N, Hunnangkul S, et al. Reproductive health and quality of life of young Burmese refugees in Thailand. Confl Health. 2010:4(1):1-9.

25. Dewachi O, Skelton M, Nguyen VK, Fouad FM, Sitta GA, Maasri Z, et al. Changing therapeutic geographies of the Iraqi and Syrian wars. The Lancet. 2014;383(9915):449-57.

26. UNHCR the UN Refugee Agency. Section 3 Evaluation of quality, access to and use of reproductive health services for refugees and internally displaced persons.

27. Baxter LM, Eldin MS, Al Mohammed A, Saim M, Checchi F. Access to care for non-communicable diseases in Mosul, Iraq between 2014 and 2017: a rapid qualitative study. Confl Health. 2018;12(1):12-5. 
28. Bader F, Sinha R, Leigh J, Goyal N, Andrews A, Valeeva N, et al. Psychosocial health in displaced iraqi care-seekers in non-governmental organization clinics in Amman, Jordan: an unmet need. Prehosp Disaster Med. 2009;24(4):312-20.

29. Chu KM, Trelles M, Ford NP. Quality of care in humanitarian surgery. World J Surg. 2011;35(6):1169-72.

30. Ekezie W, Timmons S, Myles P, Siebert P, Bains M, Pritchard C. An audit of healthcare provision in internally displaced population camps in Nigeria. J Public Health. 2018:41:1-10.

31. Merhan Q, Saeed A, Usman Ahmad R, Erum Q, Nosheen Q, Fatima Q. Assessment of health services on relevant primary health care principles in internally displaced people of Pakistan basedon SPHERE standards and indicators. J Coll Phys Surg Pak. 2011;21(5):315-6.

32. Blanchet AK, Sistenich V, Ramesh A, Frison S, Warren E, Hossain M, et al. An evidence review of research on health in humanitarian crises: preliminary findings conceptual framework. London: London School of Hygiene and Tropical Medicine; 2013.

33. Gerdin M, Clarke M, Allen C, Kayabu B, Summerskill W, Devane D, et al. Optimal evidence in difficult settings: improving health interventions and decision making in disasters. PLoS Med. 2014;11(4):e1001632.

34. Nandy R, Burnham G, Gayer M, Massaquoi MBF, Checchi F, Spiegel P, et al. Strengthening the evidence base for health programming in humanitarian crises. Science. 2014;345(6202):1290-2.

35. Samarasekera $U$, Horton R. Improving evidence for health in humanitarian crises. Lancet. 2017;390(10109):2223-4.

36. Morton MJ, Burnham GM. Iraq's internally displaced persons: a hidden crisis. JAMA J Am Med Assoc. 2008:300(6):727-9.

37. Daniels A, Teems L, Carroll CD, Santiago-Fernandez E. Crossing the quality chasm. Empl Assist Q. 2011;19:27-43.

38. OECD. Quality STANDARD FOR DEVELOPMENT EVALUATION. Paris: OECD; 2010.

39. Ayanian JZ, Markel H. Donabedian's lasting framework for health care quality. N Engl J Med. 2016;375(3):205-7.

40. Donabedian A. Evaluating the quality of medical care. Reprinted 1966 article. Milbank Q. 2005;83(4):691-729.

41. Hashemite Kingdom of Jordan, United States Agency for International Development (USAID), Primary Health Care Initiative (PHCI) Project. Quality Improvement Handbook for Primary Health Care. Initiatives. 2004.

42. Health Cluster Iraq. Results of comparison of QoC in Health Facilities in Camps (phase 1 \& 2) 2018 [Internet]. 2018. p. 1. Available from: https:// www.humanitarianresponse.info/sites/www.humanitarianresponse.info/ files/documents/files/who_irq_results_of_comparison_of qoc_asses sment_in_health_facilities_in_camps_phase120ver_all_survey.pdf.

43. Health Cluster Iraq. IRAQ: Quality of Care 2018 Analysis [Internet]. 2018. p. 1. Available from: https://www.humanitarianresponse.info/sites/www. humanitarianresponse.info/files/documents/files/who_irq_results_of_ comparison_of_qoc_assessment_in_health_facilities_in_camps_phase 12over_all_survey.pdf.

44. Global Camp Coordination and Camp Management Cluster. Camp management toolkit 2015. 2015. 282
45. Malik S. A balanced scorecard for assessing the quality \& provision of health services in UNHCR refugee camps. ProQuest Dissertations and Theses. Johns Hopkins University; 2015.

46. Harvard Humanitarian Initiative. Kobo Toolbox. 2018.

47. (IOM) IO for M. IOM Data matrix Iraq [Internet]. 2019. Available from: http://iraqdtm.iom.int/.

48. R Core Team. R: A language end environment for statistical computing. Vienna: R Foundation for Statistical Computing; 2018.

49. RStudio Team. RStudio: integrated development for R. Boston: RStudio Inc; 2019.

50. Andaleeb SS. Service quality perceptions and patient satisfaction: a study of hospitals in a developing country. Soc Sci Med. 2001;52(9):1359-70.

51. Shirley ED, Sanders JO. Measuring quality of care with patient satisfaction scores. Orthop Forum. 2016;83:1-5.

52. Saleh S, Alameddine M, Mourad Y, Natafgi N. Quality of care in primary health care settings in the Eastern Mediterranean region: a systematic review of the literature. Int J Qual Health Care. 2015;27(2):79-88.

53. Mowafi H, Spiegel P. The Iraqi refugee crisis. JAMA. 2008;299(14):1713.

54. Mowafi H. Conflict, displacement and health in the Middle East. Glob Public Health. 2011;6(5):472-87.

55. Levy BS, Sidel VW. Adverse health consequences of the Iraq War. Lancet. 2013;381(9870):949-58.

56. Al Hilfi TK, Lafta R, Burnham G. Health services in Iraq. Lancet. 2013;381(9870):939-48.

57. Leaning J, Spiegel P, Crisp J. Public health equity in refugee situations. Confl Health. 2011;5(1):1-7.

58. Banatvala N, Zwi AB. Public health and humanitarian interventions: developing the evidence base. BMJ. 2000;321:101-5.

59. Tessema GA, Laurence CO, Mahmood MA, Gomersall JS. Factors determining quality of care in family planning services in Africa: a systematic review protocol. JBI Database Syst Rev Implement Rep. 2016;14(8):103-14.

60. Coleman M. 乳鼠心肌提取 HHS Public Access. 2016;5(6):1-8.

61. Nottingham QJ, Johnson DM, Russell RS. The effect of waiting time on patient perceptions of care quality. Qual Manag J. 2018;25(1):32-45

62. Horton R. Health in the Arab world: a renewed opportunity. Lancet. 2014;383(9914):283-4.

63. Chatelard G. Iragi Refugee and IDPs : From Humanitarian Intervention to Durable Solutions. In: Calabrese J, Marret J-L, editors. Transatlantic Cooperation on Protracted Displacement: Urgent Need and Unique Opportunity. Middle Eas. 2012. p. 23.

64. Barnett-Vanes A. Armed conflict, medical training and health systems. Med Confl Surv. 2016;3699(June):1-10.

65. UNHCR the UN Refugee Agency. Health in camps. 2017;1-8.

\section{Publisher's Note}

Springer Nature remains neutral with regard to jurisdictional claims in published maps and institutional affiliations.

Ready to submit your research? Choose BMC and benefit from

- fast, convenient online submission

- thorough peer review by experienced researchers in your field

- rapid publication on acceptance

- support for research data, including large and complex data types

- gold Open Access which fosters wider collaboration and increased citations

- maximum visibility for your research: over $100 \mathrm{M}$ website views per year

At BMC, research is always in progress.

Learn more biomedcentral.com/submissions 